\title{
Entrepreneurial Education for Finger Disabilities Deaf Talk Training through Processing Bread
}

\author{
Novfitri LandongNamora Sihombing, Siti Rozinah, Andri Meiriki \\ Institute of Technology and Business Ahmad Dahlan Jakarta \\ novfitri.lns@gmail.com
}

\begin{abstract}
Competition increasingly harsh world of work and a lot of people who have not equalized the ability of the deaf to make them more challenging to grow and live independently. Still, there who think that people with smallpox are the ones who made the other person. Though there are still people with disabilities who have the talent and it can lift more appreciated in rank than the healthy surrounding environment. Could take the lesson that not all people with disabilities harm others. Normal Supposedly embarrassed and could make the experience from these people if see the concept, entrepreneurship be entrepreneurial while their entrepreneurship taste of the French language "Enterprende" which means to perform or carry out, while understanding the entrepreneur is one who organizes, manages and bears the risk of the business. Now, this entrepreneur also often include the inventor and developer of business, which can recognize and exploit opportunities. Convert chances into something worth performed and marketed. To grow themselves disabilities deaf, our team community service to choose the Finger Talk communities, as a forum to educate entrepreneurship training and processing and bread baking for friends disabilities deaf, from the training expected to foster the entrepreneurial spirit for disabilities friends and have expertise in making bread so that it can generate several kinds of food with some flavor.
\end{abstract}

Keywords: entrepreneurship, community, disabilities deaf

\section{INTRODUCTION}

Humans have a mental disability or sometimes make him feel confident in performing daily activities. Still, they are part of Indonesian citizens who have equal footing with other citizens who do not suffer from a disability and psychological. So that they have daily activities they need to get serious attention.

Since 2006, the United Nations has adopted the Convention rights of persons with a disability, up to now ratified by 164 countries, including Indonesia, Disability results from an interaction between the individual functional limitations (mobility, vision, hearing, and communication) with the environmental conditions that hinder active participation and useful in society.

Population growth with disabilities each year has increased. Recorded in 2010, the number of persons with disabilities many 11.58 million people (Media Center, 2010). then the Central Statistics Agency (BPS) recently released data of the National Labor Force Survey Unit (Sakernas) in 2017, where the population of persons with disabilities has grown almost three times more than in 2010, reaching 32.60 million. Despite the growth of people with disability increased. However, the number of dependency or age instead of the labor force number is still 
Entrepreneurial Education For Finger Difabelitas Deaf Talk Training Through Processing Bread Sihombing, Rozinah, Meiriki

quite high, amounting to $48.82 \%$ of the total population there (Sakernas, 2017). More see the following picture:

Image 1. Data Growth Disabilities 2017

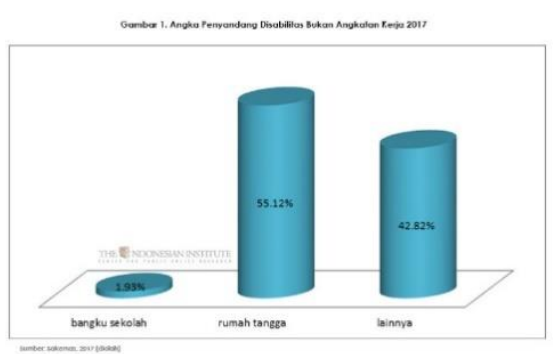

Figures such dependence is high, where the productive sector of the population that plays a role in the education level distribution amounted to only $1.93 \%$. While in the consumer sector as some domestic delivery reaches more than half $(55.12 \%)$ of the total workforce. Then, if it based on the category of employment sectors, study the Economic and Social Research Institute (LPEM) at the University of Indonesia in 2017, when people with disabilities find jobs dominated the informal sector. see the following picture

Image.2.Gambar Data From Public Sector Disabelitas

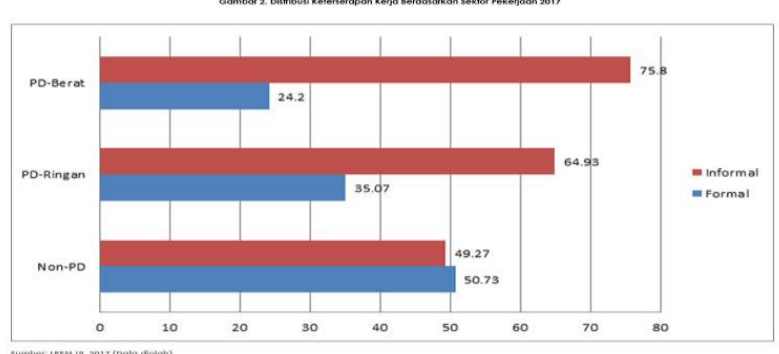

Comparison of the proportion of the labor force formal and informal sector is the highest in the population of persons with disabilities by weight, with the percentage working in the informal sector, reached $75.8 \%$. From these data that the majority of the group disabilities did not have a job, but every citizen has the right to have a job, but the task of employment available in the public domain as if he would not intend for the disabilities group.

At the seminar, International Day of Persons with Disabilities (HIPENCA) said people with disabilities deaf. Such data explains 15\% are raise disabilities deaf, deafness experienced by a would-be problematic in the social, emotional, and mental. Problems that arise from deafness, among others, issues of language development, speech skills, social, emotional, intellectual, and ultimately hinder the development of the aspects of life and humanity and also narrow the educational and employment opportunities.

Competition increasingly harsh world of work and a lot of people who have not equalized the ability of the deaf to make them more challenging to grow and live independently. Still, there who think that people with smallpox are the ones who made the other person. Though there are still people with disabilities who have the talent and it can lift more appreciated in rank than the healthy surrounding environment. Could take the lesson that not all people with disabilities harm others. Normal Supposedly embarrassed and could experience from these people(Wajdi, 2019).

An understanding of entrepreneurship continues to experience growth the increasingly important role of entrepreneurs in the community activities, theories concerning 
Entrepreneurial Education For Finger Difabelitas Deaf Talk Training Through Processing Bread Sihombing, Rozinah, Meiriki

entrepreneurship should be able to improve basic principles that explain the meaning of entrepreneurship or entrepreneurship as well the rules of interconnected elements encourage the emergence of self-employment or entrepreneurship, this understanding should be able to provide the ability to predict results and activities are entrepreneurial. They can also provide instructions on how to act right for entrepreneurs to deal with a particular pattern.

If we see the concept, said entrepreneurship subtitle be entrepreneurial while their entrepreneurship taste of the French language "Enterprende," which means to perform or carry out, while definition entrepreneur is one who organizes, manages, and bears the risk of the business. Now, this entrepreneur also often include the inventor and developer of business, which can recognize and exploit opportunities. Convert chances into something worth performed and marketed. Entrepreneurial need to able to provide added value through time, through the effort expended, through capital or money to start a business., Skill utilization, are willing to bear the risk if the market was full of competition and realize the benefit derived from the work done.

Entrepreneurs considered a catalyst that is aggressively trying to change the world of business. The entrepreneur is also the people who have free thought (independent) who dared to raise the idea that different from the general public thought. To grow itself disabilities deaf, our team community service to choose the communities Finger Talk, as a forum to educate entrepreneurship training and processing and bread baking for disabilities deaf, from the training are expected to foster the entrepreneurial spirit for limitations and have expertise in making bread so that it can generate several kinds of food with some flavor.

\section{METHOD}

On the community service is done by the environmental approach, approach financial approach, the approach displacement, approach business opportunities, and strategic approach to entrepreneurial thinking.

\section{Environmental outlook}

This approach is related to external factors that influence the pattern of life, so it has potential or not. It has the potential to become entrepreneurs. This factor can be a positive or negative effect on the emergence of a desire to start a business as an entrepreneur. These factors include the state of the institution, in this case, the state institution is a community where members talk finger is disabilities, deaf friends, while the values of the public, that the benefits of the people that there is that the presence of friends disabilities deaf often underestimated by the public. We tried to change the phenomenon so that they do not Kagi regard as public disabilities friends who can not work.

\section{Finance approach}

The approach focuses on the process of planting and growing the entrepreneurial capital as the parties viewed only as a process of development or double money. In contrast, another view that found financial operations is a part of entrepreneurial activity. For this, the team tries to explain how to get cash or capital to invested and is grown in its efforts to provide financial education to prospective new businesses. So that they can plan and process and use the money as working capital properly.

\section{Transfer approach}


Entrepreneurial Education For Finger Difabelitas Deaf Talk Training Through Processing Bread Sihombing, Rozinah, Meiriki

This approach based on the phenomenon that occurs in an experienced group that experienced group atmosphere can encourage or inhibit appearance factors that cause it to become entrepreneurs.

The phenomenon occurs to physical limitations and expertise, no education and guidance to them, do not have the opportunity to become an entrepreneur, through community service. The team tries to alter shift to a friend's disabilities of which do not have the expertise, which may not be able to work, which could not be entrepreneurs open businesses.

\section{Approach Business Opportunities}

This approach focuses attention on the problem of the growth opportunities in entrepreneurship, finding the business idea further develop the business, and then take advantage of business opportunities. Is an essential thing, in this case, our team of community service to help friends disabilities to make a business idea, develop business and to run a business so that they have an understanding of the market and considers creativity are two essential aspects they need to know when they want to be an entrepreneur

\section{Strategic approach}

In approach more importance in the planning process in a successful entrepreneurial approach, in this case, is unique as a unique market, employees are individual.

\section{- A typical market}

In this case, the emerging market segments for utilizing and empowering disabilities deaf friends in the operations so that the market segment is not only the general public but allocated to the limitations.

\section{- Typical workforce}

Businesses that are developed and executed by utilizing the skills or talent remarkable characteristic of labor-owned. In this respect, the skills and talents that owned disabilities deaf friends.

\section{RESULT AND DISCUSSION}

\section{Community Overview Finger Talk}

Finger Talk as one community for deaf friends located on the street Pinang Raya No. 37, East Pamulang, South Tangerang City, Banten, Dissa Syakina Ahdanisa, owner Fingertalk been a volunteer worker in Nicaragua, Central America. There Disa friends and take care of deaf friends. When she returned to Indonesia, she a concept to create a community for friends deaf to open Community Fingertalk in May 2015 so accommodate friends deaf by providing some training in cooperation with several institutions to tried to give employment for people with disabilities, especially the hearing impaired. Where those around him often underestimate deaf people. Expected that with the establishment of Fingertalk, deaf people can also work as an average person in general. Below is the image of the location of the finger-talk community.

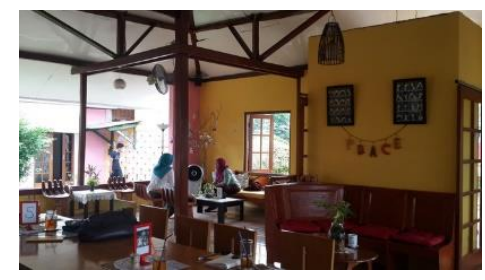


Entrepreneurial Education For Finger Difabelitas Deaf Talk Training Through Processing Bread Sihombing, Rozinah, Meiriki

\section{Training locations}

\section{Image.3. Location finger Talk}

Deaf Cafe Fingertalk, located at Jalan Cinere Raya No. 26-29, Cinere, Limo, Depok, a training ground processing of bread and entrepreneurial education, which is one of our team community services, the place already available equipment, and supplies for bread processing training and design for the opening of the bakery as the result of after the training run. Here's where training and the production of bread finger talk:

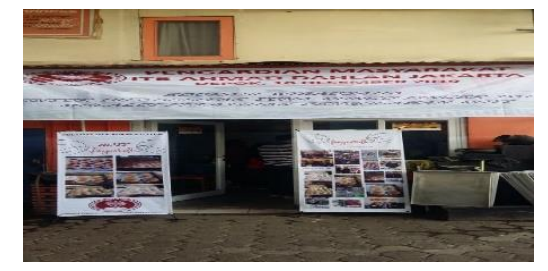

Image.3. Locations and Production Sites Finger Talk

\section{Trainees}

Participants of this training followed by four (4) members comprising three (3) persons who are deaf and 1 (one) constructor deaf community). As for the participants, namely: Ali Wafa (Trustees of the deaf community), Rilda Trictora, Ria Anggraini, Revi Anicanti. 3 (three) is deaf people included because they are particularly interested in the field of culinary business Enterprises Bakeries.

\section{Implementation Activities Community Service}

\section{a. Training methods}

In the implementation of training processing bread in Community, Finger Talk provides specialized training disabilities about designing a new business field of culinary. This is provided that they know about opening a new business field of culinary, the expectations of the team community service which runs community service are, later on, friends disabilities deaf can work with the culinary business open so friends disabilities deaf can perform quite differently in society, which no longer imposes the community. Not only that, but friends also disabilities deaf will share the knowledge and expertise to other disabilities friends who want to know and learn the culinary business processing and open a practical and tasty bread.

b. Execution time

Event processing training implementation bread made with two (2) periods with a period of 6 (six) months. 3 (three) months were checking equipment and supplies as well as the introduction of raw materials as well as the essential practice of processing bread. 3 (three) months before training both the strengthening of basic training (early), so that they have the expertise and skills better compare initial training. In the second bread processing training, they were taught some kinds and models of bread before they get in the first training. So that they have the insight and knowledge of various shapes and tastes of food.

\section{c. Baking Process}

\section{The first step: Shopping ingredients to make bread needs}

To make bread during this training takes several components. In this stage, the material was prepared by a team of lecturers who perform community service. In contrast, the equipment and support equipment bread making is already owned by the community finger talk such as pan, Mixer and Oven-Electric, and others, while the raw material for making bread that is required can be seen in the figure below: 
Entrepreneurial Education For Finger Difabelitas Deaf Talk Training Through Processing Bread Sihombing, Rozinah, Meiriki
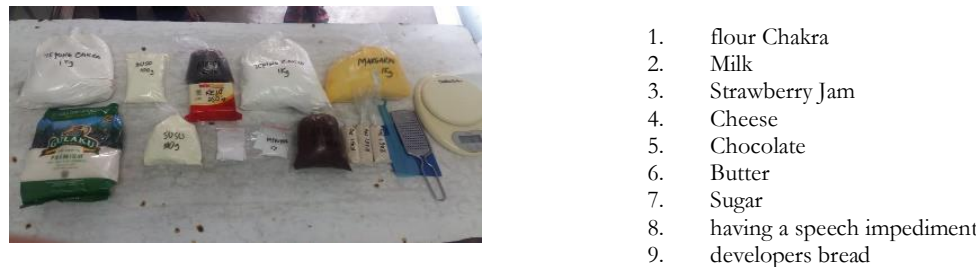

Image.4. Ingredients For Baking

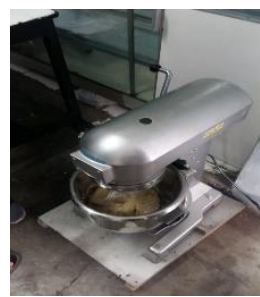

Image.5. Mixer For Treatment bread

\section{Step two: introduce the ingredients to make bread}

In the second process, participants were introduced to tools, equipment, and materials needed and explain how to weigh the raw materials required to make bread to the scales to the size necessary to make one dough.
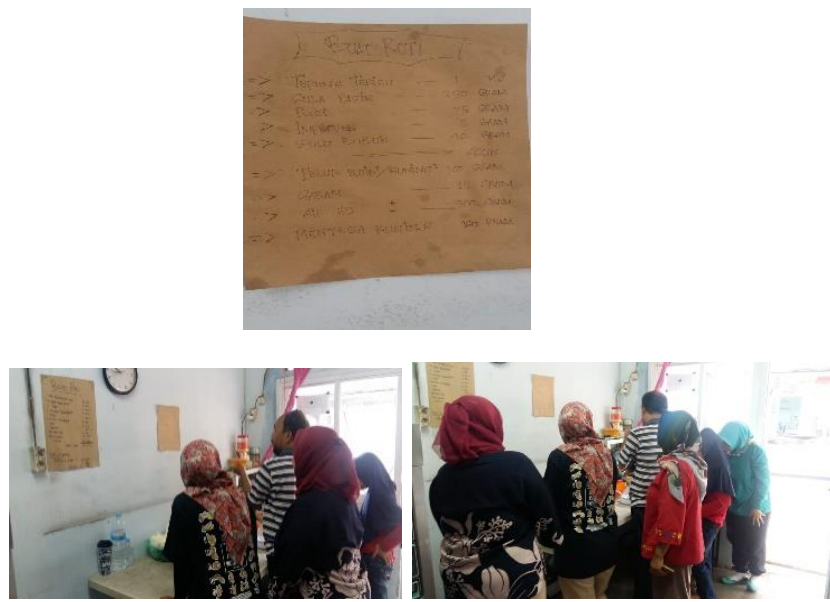

Image 6. Introducing And Explains Materials Bread

\section{The third step: to explain and practice of making bread}

The next step is to describe the actions of making bread that is practical, easy, and delicious. Each participant is allowed to practice direct processing of bread from start to weigh raw materials, forming loaves of food in the oven and bake until the bread wrapping ripe. As shown below:

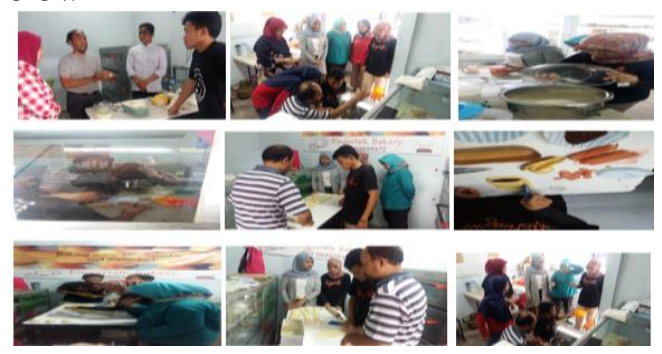

Image 7. Processing Practice Rot

\section{Step Four: product inspection}

In this stage, the bread ripe checked back. Done to determine the bread made is already marketable or still needs to be improved if the terms of the bread quality were 
Entrepreneurial Education For Finger Difabelitas Deaf Talk Training Through Processing Bread Sihombing, Rozinah, Meiriki

satisfactory, then the food is ready for the market. The examination of this product as shown below;

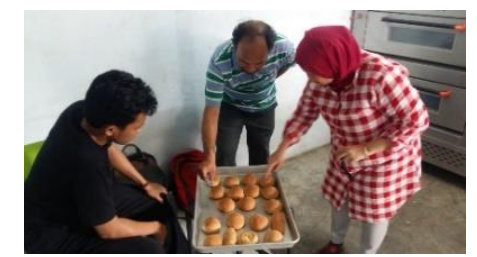

Image 8. Examination Bread That Has Cooking

\section{Step five: packaging products}

Once the bread has escaped the examination phase, the next process is the packaging or wrapping bread, packaged neatly so that the food ready to be sold at fairs, schools, Deaf Cafe, and car wash as well as other places. The following picture bread packaging is available to be marketed.
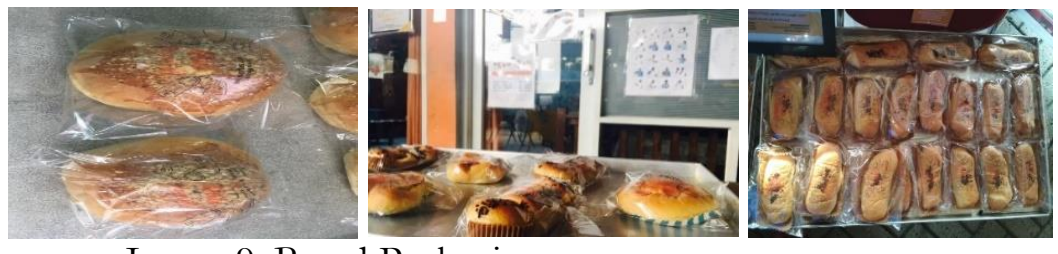

Image 9. Bread Packaging

\section{d. Bread Product Marketing}

\section{Deaf Cafe and Car Wash Finger Talk}

Deaf Cafe and Car Wash Finger Talk is one that employs people with disabilities deaf, is established wants to raise the degree of persons with disabilities located in 32 Jalan Raya Cinere Depok. This bread sold in Deaf Cafe And Car Wash facilitates customers to find and buy food. Because of the production site adjacent to the bread-making Deaf Cafe FingerTalk, all the food was packaged and can be directly marketed or traded.

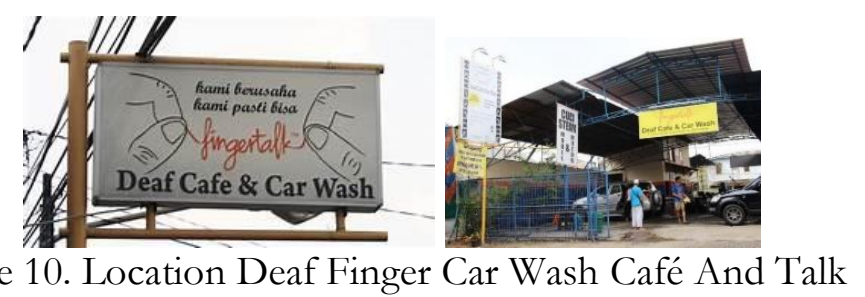

\section{Bazar}

Image 10. Location Deaf Finger Car Wash Café And Talk

Finger Bread Talk in promoting and selling their products followed Bazar for 1 (one) day at the Open University on November $23^{\text {rd, }} 2019$, in an event commemorating the National Teacher. As shown below:

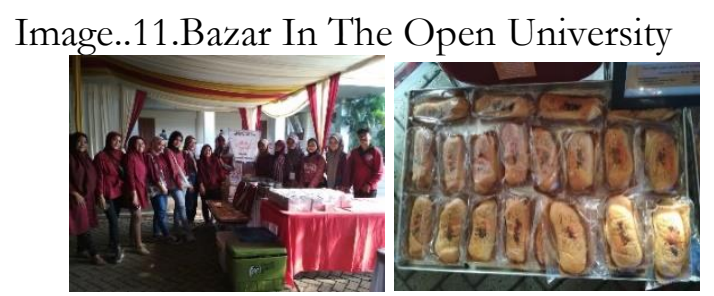

\section{Elementary school ASSAKINAH}

In addition to the Deaf Cafe And Car, Wash Finger Talk Bread Finger Talk marketed in the cafeteria SD ASSAKINAH, to meet the needs allowance school children ASSAKINAH every day because of the price of bread sale very economical price, and 
Entrepreneurial Education For Finger Difabelitas Deaf Talk Training Through Processing Bread Sihombing, Rozinah, Meiriki

very affordable among school students ASSAKINAH, so every day talks finger bread sold.

\section{General}

Marketing talk any finger bread was done for the general public, our community service team put a banner on the outside near the Deaf Cafe and Car Wash, we do the general public, or that is a bakery works disabilities, deaf children. it may look like the image below:

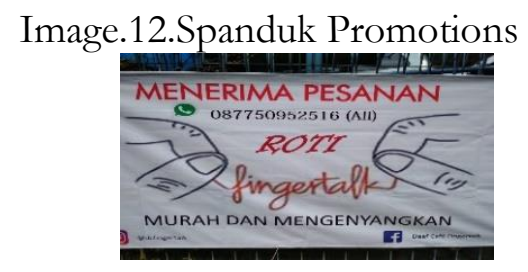

\section{e. Results Provided by Participant}

\section{Economic aspects}

The training program teaches coaches bread processing can provide income that can provide income for friend's disabilities; this result can increase revenue that can help each day spending needs.

\section{2. aspects of knowledge}

Initially, disabilities friends do not understand and appreciate the processing of making bread. Here they explained what ingredients are needed to make bread, and taught how to make a practical and tasty bread.

\section{3. aspect Skills}

Once they get this training, a friend's disabilities become more skilled in producing various types of bread.

\section{4. aspects of experience}

When they get into coaching and excellent food. The result is bread made already can be exhibited in a bazaar, it can add to their experience. It can look like the image below:

Image.13.Bazar On National Teacher Day At UT convention Center

\section{Community social}

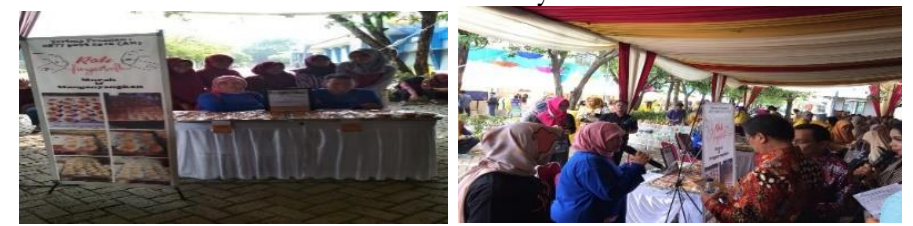

When they introduce and sell their food products to schools and some the study as well as hospitals and even to several cafe areas South Tangerang. It trains them to socialize with the community well.

\section{CONCLUSION}

With the entrepreneurial education and training to bread, friends disabilities deaf can supplement their income to everyday life.

Friends disabilities deaf to understand and appreciate entrepreneurship knowledge and processing of bread making. Here they explained what ingredients are needed to make bread, and taught how to make a practical and tasty bread.

Their position can already equal to the general public, and they will no longer be a burden to society because they have become a culinary entrepreneur, namely bakery. 
Entrepreneurial Education For Finger Difabelitas Deaf Talk Training Through Processing Bread Sihombing, Rozinah, Meiriki

\section{REFERENCE}

Adji Revelation, Suwerli, \& Suratno. Editor: Yusuf Setiawan. S, \& Utami Diyah .P. (2007). "Entrepreneurship." Jakarta: publisher

Entrepreneurship book "Building Business Success Since Early Age," Salemba Four (2011), Jakarta(University of Mercu Buana)

SekretariatJendral Ministry of Social Affairs and Social Welfare Information Center. (2002.)"People with Disabilities." Jakarta

Ministry of Social Affairs, (2006)"Criteria Free Persons with Physical Disabilities," Jakarta: Directorate General of Service and Social Affairs Rehabiktas.

Directorate General of Social Rehabilitation of People with Disability. (2010)"Total Communications Implementation Guide For People With Disabilities Deaf-Mute."

SB Today Lubis, (2014)" Entrepreneurship, Issue 1/3 SKS / "Modules 1-9, ISBN 9789790116146, South Tangerang: The Open University, 2014.

Wajdi, M. B. N. (2019). Trauma Healing pada Penderita Depresi di Nganjuk. Janaka, Jurnal Pengabdian Masyarakat, 1(2), 27-32. 